\title{
Fabrication of Press-molded Products Using Bamboo Powder
}

\author{
Shinji Ochi \\ AssociateProfessor, Niihama National College of Technology \\ 7-1 Yagumo-choNiihama, Ehime, Japan \\ Tel: 81-897-377-742Ｅ-mail: s_ochi@mec.niihama-nct.ac.jp
}

Received: October 8, 2011 Accepted: November 2, 2011 Published: January 1, 2012

doi:10.5539/jmsr.v1n1p156 URL: http://dx.doi.org/10.5539/jmsr.v1n1p156

\begin{abstract}
This paper describes the mechanical properties of press-molded products using bamboo powder. Bamboo powder can be hot press molded much like plastics. In the present study, tensile and flexural strength as well as the hardness of the molded products using bamboo powder were examined. The tensile and flexural strengths of the bamboo powder products increased with increasing molding temperature, up to $240^{\circ} \mathrm{C}$. The materials possessed tensile and flexural strengths of 18 and $33 \mathrm{MPa}$, respectively. These strengths indicated nearly identical that of polyethylene and polypropylene.
\end{abstract}

Keywords: Bamboo powder, Hot press, Tensile strength, Flexural strength, Vickers hardness

\section{Introduction}

Plastic materials are used in various fields for many reasons, including their light weight, high specific strength, good processing ability and the ease by which they can be mass-produced. However, these uses have many disadvantages, including the depletion of fossil fuels and a lack of space for the associated waste. Clearly, it is becoming increasingly difficult to live sustainably in the global environment. Solutions to these problems must involve the development of appropriate waste treatment processes and methods for recycling waste as soon as possible. From this perspective, a material that does not use fossil fuels and reduces greenhouse gas emissions must be developed. Over the past few years a considerable number of studies have been conducted on biodegradable composites containing biodegradable plastics reinforced biodegradable natural fibers, such as flax(T. Stuart, 2005), ramie(T. Stuart, 2005), jute(T. Stuart, 2005; Okubo K.,2002), bamboo(Okubo K.,2002), pineapple(W. Liu et al., 2005), kenaf(T. Nishino, 2003), henequen(P. J. Herrera-Franco \& A. Valadez-González, 2004) and hemp(A. K. Mohanty, 2004) fibers.

In the past, bamboo was used as part of daily life (e.g., bamboo shoots for food and stalks for building materials). Recently, however, bamboo forests have fallen into ruin because of the appearance of plastic products and the import of inexpensive bamboo shoots. The present study investigated whether bamboo can be effectively used to replace plastic materials. The press-molded products were fabricated from bamboo powder, and the tensile strength, flexural strength and hardness of the resultant products were examined. These measured properties were subsequently compared to the mechanical properties of common plastic materials.

\section{Experimental Procedures}

\subsection{Materials}

In the present study, the bamboo powder (Miki Takezaiten, Japan) was preserved using a constant temperature $\left(23^{\circ} \mathrm{C}\right)$ and relative humidity $(50 \% \mathrm{RH})$ container. Photographs of the bamboo used in the present study are shown in Fig. 1. The exterior and interior surfaces of bamboo are shown in Fig. 1a. As indicated in Fig. 1b, the cross section of bamboo shows abundant fibers on the hull side of the bamboo and sparse fibers on the endodermis side.

Photographs of bamboo powder are shown in Fig. 2; an overview in Fig. 2a and a magnified view in Fig. 2b. As shown in Fig. 2a bamboo powder appears fine and uniform, but microscopic parenchyma cells and fiber bundles (approximately 100-200 $\mu \mathrm{m}$ long and 5-10 $\mu \mathrm{m}$ in diameter) are seen under magnification (Fig. 2b). Bamboo is composed of parenchyma cells that store nutrients and vascular bundles that protect the trachea and the sieve tube. The main architectural components are cellulose (60\%), lignin (20-30\%) and hemicelluloses (10-20\%) (S. Jain, R. Kumar \& U.C. Jindal, 1992). 


\subsection{Molding method}

The specimens were fabricated using a hot press machine and a metallic mold. Specifically, to test specimens made under varying conditions, the bamboo powder was added to the metallic mold and held at four different temperatures $\left(160,180,200\right.$ and $\left.240^{\circ} \mathrm{C}\right)$ for $5 \mathrm{~min}$ and pressed at $72 \mathrm{MPa}$ for $1 \mathrm{~min}$. The tensile-test specimens were dumbbell-shaped with a width of $10 \mathrm{~mm}$, a thickness of $3 \mathrm{~mm}$, parallel portion length of $86 \mathrm{~mm}$ and a total length of $152 \mathrm{~mm}$.

The flexural-test specimens were made by machining tensile-test specimens. Dimensions of the flexural-test specimens were $80 \times 10 \times 3 \mathrm{~mm}$.

Vickers hardness-test specimens were made a manner identical to that for the tensile-test specimens. Dimensions of the hardness-test specimens were $25 \times 25 \times 3 \mathrm{~mm}$.

\subsection{Mechanical testing}

Tensile tests and three-point flexural tests were conducted using a testing machine(Aiko engineering Model 1301D), following JIS K7162. Tensile tests were performed at a strain rate of $0.02 / \mathrm{min}$ and a gauge length of 50 $\mathrm{mm}$. Flexural tests were performed at a crosshead speed of $1 \mathrm{~mm} / \mathrm{min}$ and a span length of $48 \mathrm{~mm}$. Five specimens were prepared and analyzed. A 95\% confidence interval was calculated by statistical analysis.

Vickers hardness of the molded products was measured with a hardness examination machine(SHIMADZU HMV-ADW) following JIS Z 2244. This test was conducted at an examination power of $980.7 \mathrm{mN}$ and a hold time of 30 s. Twenty regions on the molded products were prepared and analyzed.

\section{Results and Discussions}

\subsection{Fabrication of press molded products}

Photographs of the fabricated press molded products using bamboo powder are shown in Fig. 3, with specimens molded at $160,180,200$ and $240^{\circ} \mathrm{C}$ shown in Figs. $3 \mathrm{a}, \mathrm{b}$, c and d, respectively. As seen in these photographs, the color of the specimen molded at $160^{\circ} \mathrm{C}$ is pale yellow; however, the color darkened with rising molding temperature is the specimen exhibits a strong brown color at $240^{\circ} \mathrm{C}$. These results suggest that specimens browned on account of carbonization between 180 and $240^{\circ} \mathrm{C}$.

Photographs of the surfaces of the different specimens observed using bright field microscopy are shown in Fig. 4, with specimens molded at $160,180,200$ and $240^{\circ} \mathrm{C}$ shown in Figs. $4 \mathrm{a}, \mathrm{b}, \mathrm{c}$ and d, respectively. As shown in these figures, at $160^{\circ} \mathrm{C}$, the fiber bundle and the parenchyma cell are clearly divided. On the other hand, it becomes increasingly difficult to distinguish the interface between the fiber bundle and the parenchyma cell with rising molding temperature. At $240^{\circ} \mathrm{C}$, all aspects become almost a uniform brown, making the interface between the fiber bundle and the parenchyma cell indistinguishable.

The relationship between the density of the specimens and molding temperature is shown in Fig 5, and indicates that the density of specimens increased with rising molding temperature. Recall from Fig. 4, that the interface between fiber and parenchyma cell becomes increasingly difficult to observe with rising molding temperature. It is considered that as a result of the increased bonding between fiber and parenchyma cell with rising molding temperature, the density of the molded products increased. The densities of products molded at 160 and $240^{\circ} \mathrm{C}$ are 1.26 and $1.40 \mathrm{~g} / \mathrm{cm}^{3}$, respectively.

\subsection{Tensile and flexural properties}

The relationships between tensile strength and modulus and molding temperature are shown in Figs. 6 and 7 , respectively. As shown in these figures, both tensile strength and modulus increase with rising molding temperature. For the specimen molded at $240^{\circ} \mathrm{C}$, tensile strength and modulus were $17.9 \mathrm{MPa}$ and $5.7 \mathrm{GPa}$, respectively.

Photographs of the fracture behavior after tensile testing are shown in Fig. 8. For the specimen molded at $160^{\circ} \mathrm{C}$, delamination occurs between the fiber and the parenchyma cell. A pull out of fibers was observed in specimens fabricated at $180^{\circ} \mathrm{C}$. At $200^{\circ} \mathrm{C}$, a fracture of the fiber bundle was observed in a part of the specimens. For the specimen molded at $240^{\circ} \mathrm{C}$, the fiber bundles fractured, and the fiber bundle and the parenchyma cell mixed homogeneously.

The relationships between flexural strength and modulus and molding temperature are shown in Figs. 9 and 10, respectively. As shown in these figures, flexural strength and modulus increase with rising molding temperature. For the specimen molded at $240^{\circ} \mathrm{C}$, flexural strength and modulus were $33.0 \mathrm{MPa}$ and $10.1 \mathrm{GPa}$, respectively. Photographs of the fracture surfaces after flexural testing are shown in Fig. 11. For the specimens molded at 160 
and $180^{\circ} \mathrm{C}$ delamination can be seen between the fiber bundle and the parenchyma cell, and bonding between the fiber bundle and the parenchyma cell is poor. At $200^{\circ} \mathrm{C}$, a fracture of the fiber bundle is seen in a part of the specimen. For the specimen molded at $240^{\circ} \mathrm{C}$, the fiber bundle was difficult to discern, and the fiber bundle and the parenchyma cell mixed homogeneously.

Results from the tensile and flexural tests indicate that when the molding temperature is low, the bonded parts of the fiber bundle and the parenchyma cells become locations where sites of possible fracture. On the other hand, as the molding temperature rises, the bond strength of the fiber bundle and the parenchyma cell increases although the strength of the fiber decreases. Hence, the fiber bundle controls the strength of the molded product. When the molding temperature is low, it is possible that a high strength is obtained because the strength of the fiber has not deteriorated. In the present study, the specimen fabricated using a high molding temperature showed high strength. In the case of a low molding temperature, the bonding strength between the fiber and the parenchyma cell is weak and subsequently results in locations where fractures begin; even though the deterioration of fiber strength has not yet occurred according to the ref. (G. Testa, et al., 1994). In the case of a high molding temperature, flaking off of the fiber and the parenchyma cell is not seen, and the bond strength is high. As a result, it can be said that the adhesive power of bamboo powder greatly influences the strength of molded products from the strength of its fibers when the powder is molded using a hot press.

The tensile strength of common plastic materials, polyethylene and polypropylene, are 15 and $30 \mathrm{MPa}$, respectively (Hull \&Clyne, 1996). Measurements of the press molded product using bamboo powder indicated a tensile strength nearly identical to that of polyethylene. The flexural strengths of polyethylene and polypropylene are 30 and 50MPa, respectively (Hull \&Clyne, 1996). As for flexural strength, the flexural strength of the press molded product using bamboo powder approached that of polyethylene.

\subsection{Vickers hardness}

The results of the Vickers hardness tests are shown in Fig. 12. Vickers hardness increased with rising the molding temperature, up to $200^{\circ} \mathrm{C}$, however it leveled off thereafter. The tensile and flexural strength and modulus of press molded products increased with a rising molding temperature, but the Vickers hardness was not increase more than $200^{\circ} \mathrm{C}$. Vickers hardness was HV0.1 33.7 at $240^{\circ} \mathrm{C}$. The color on the surface of the specimen tended to darken with the rising molding temperature. Because the surface of the specimen is thought to becoming a close cover with the bamboo fiber melted, cavities disappeared. Furthermore, because bamboo was carbonized, an improvement of the hardness with rising molding temperature.

\section{Conclusion}

The purpose of the present study is to investigate whether bamboo material is an effective replacement for plastic material. Press molded products were made from bamboo powder and examined for their tensile strength, flexural strength and hardness. Results are summarized as follows:

1) Bamboo powder could be hot press molded. The press molded product using bamboo powder had a density of approximately $1.3 \mathrm{~g} / \mathrm{cm}^{3}$.

2) The tensile strength and flexural strength of press molded products fabricated at $160-240^{\circ} \mathrm{Cincreased}$ with rising molding temperature. For the specimen molded at $240^{\circ} \mathrm{C}$, the tensile strength was $17.9 \mathrm{MPa}$ and the flexural strength was $33 \mathrm{MPa}$. The strength of the molded product increased with rising molding temperature because of an increase in the bonding strength of the bamboo powder. On the other hand, when molding temperature was low, measured strength was low because the bonding strength was poor.

3) Vickers hardness increased with rising molding temperature. The Vickers hardness of the specimen molded at $240^{\circ} \mathrm{C}$ was HV0.1 33.7.

\section{References}

A. K. Mohanty, A. Wibowo, M. Misra, \& L. T. Drzal. (2004).Effect of process engineering on the performance of natural fiber reinforced cellulose acetate biocomposites. Composites Part A: Applied Science and Manufacturing, Vol. 35, 363-370. http://dx.doi.org/10.1016/j.compositesa.2003.09.015

D. Plackett, T. L. Andersen, W. B. Pedersen, \& L. Nielsen. (2003). Biodegradable composites based on polylactide and jute fibres.Composites Science and Technology, Vol. 63, 1287-1296. http://dx.doi.org/10.1016/S0266-3538(03)00100-3

G. Testa, A. Sardella, E. Rossi, C. Bozzi, \& A. Seves. (1994). The kinetics of cellulose fiber degradation and correlation with some tensile properties. Acta Polymer, Vol. 45, 47-49. http://dx.doi.org/10.1002/actp.1994.010450109 
Hull , \& Clyne. (1996). An Introduction to Composite Materials Second edition. Cambridge.

Okubo, K. \& Fujii, T. (2002). Eco-Composites Using Bamboo and Other Natural Fibers and Their Mechanical Properties. Proceedings of International Workshop on "Green” Composites, 17-21.

P. J. Herrera-Franco \& A. Valadez-González. (2004). Mechanical properties of continuous natural fibre-reinforced polymer composites. Composites Part A: Applied Science and Manufacturing, Vol.35, 339-345. http://dx.doi.org/10.1016/j.compositesa.2003.09.012

S. Jain, R. Kumar, \& U.C. Jindal. (1992). Mechanical behaviour of bamboo and bamboo composite. J. Mater. Sci., 27, 4598-4604. http://dx.doi.org/10.1007/BF01165993

T. Nishino, K. Hirao, M. Kotera, K. Nakamae, \& H. Inagaki, (2003). Kenaf reinforced biodegradable composite. Composites Science and Technology, Vol. 63, 1281-1286. http://dx.doi.org/10.1016/S0266-3538(03)00099-X

T. Stuart, Q. Liu, M. Hughes, R.D. McCall, H.S.S. Sharma, \& A. Norton. (2005). Structural biocomposites from flax_Part I: Effect of bio-technical fibre modification on composite properties. Composites Part A: Applied Science and Manufacturing, 393-404. http://dx.doi.org/10.1016/j.compositesa.2005.06.002

W. Liu, M. Misra, P. Askeland, L. Drzal, \& A. K. Mohanty. (2005). 'Green' composites from soy based plastic and pineapple leaf fiber: fabrication and properties evaluation. Polymer, Vol. 46, $2710-2721$. http://dx.doi.org/10.1016/j.polymer.2005.01.027
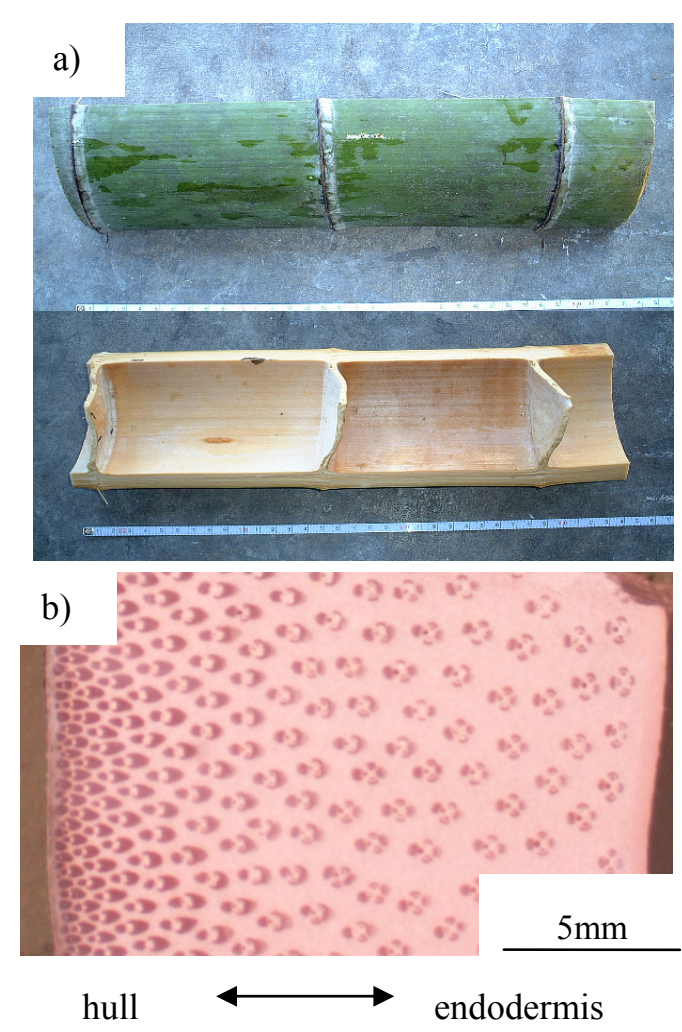

Figure 1. Photographs of bamboo

a) interior and exterior and b) cross section 

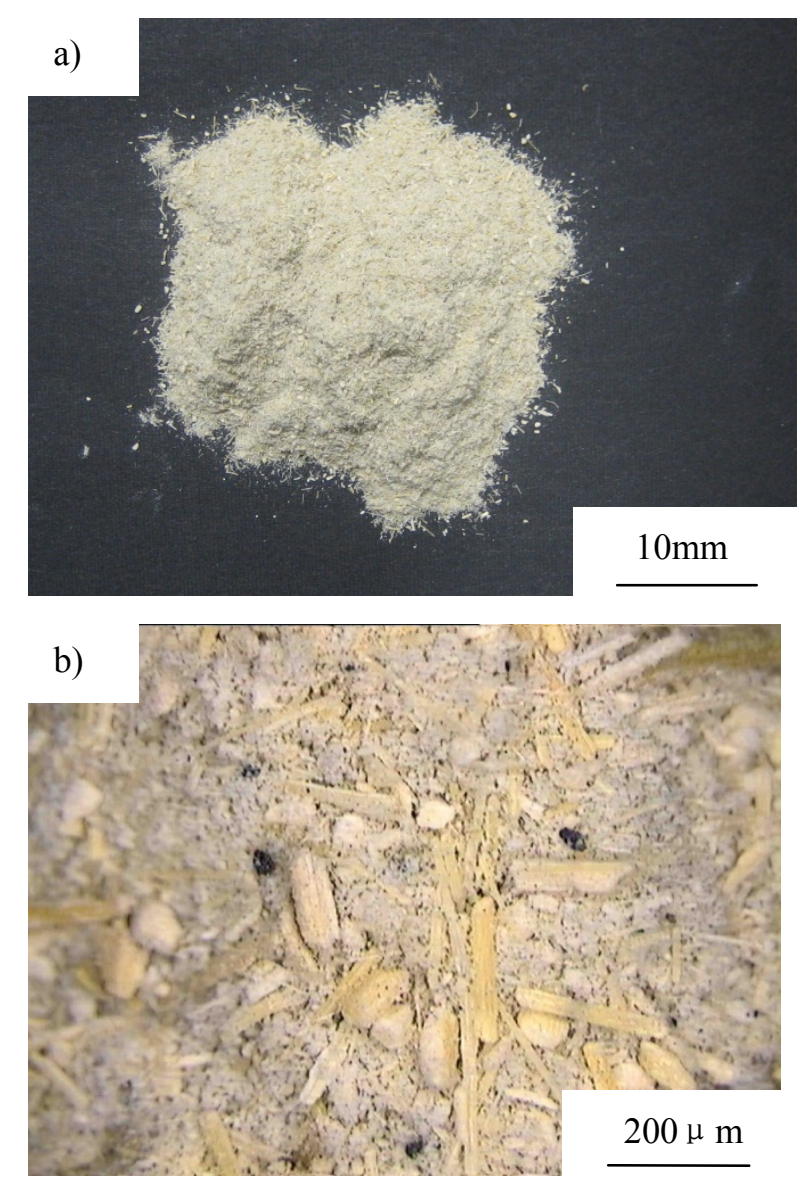

Figure 2. Photographs of bamboo powder

a) overview and b) magnified
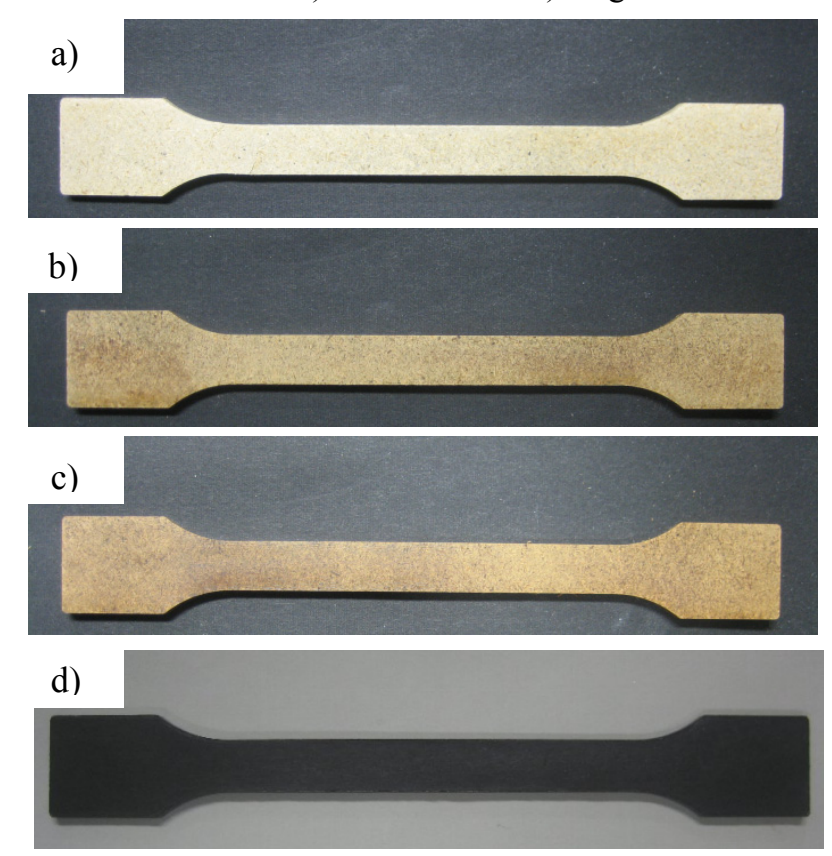

$20 \mathrm{~mm}$

Figure 3. Photographs of specimen (aspect)

a) 160 , b) 180 , c) 200 and d) $240^{\circ} \mathrm{C}$ 

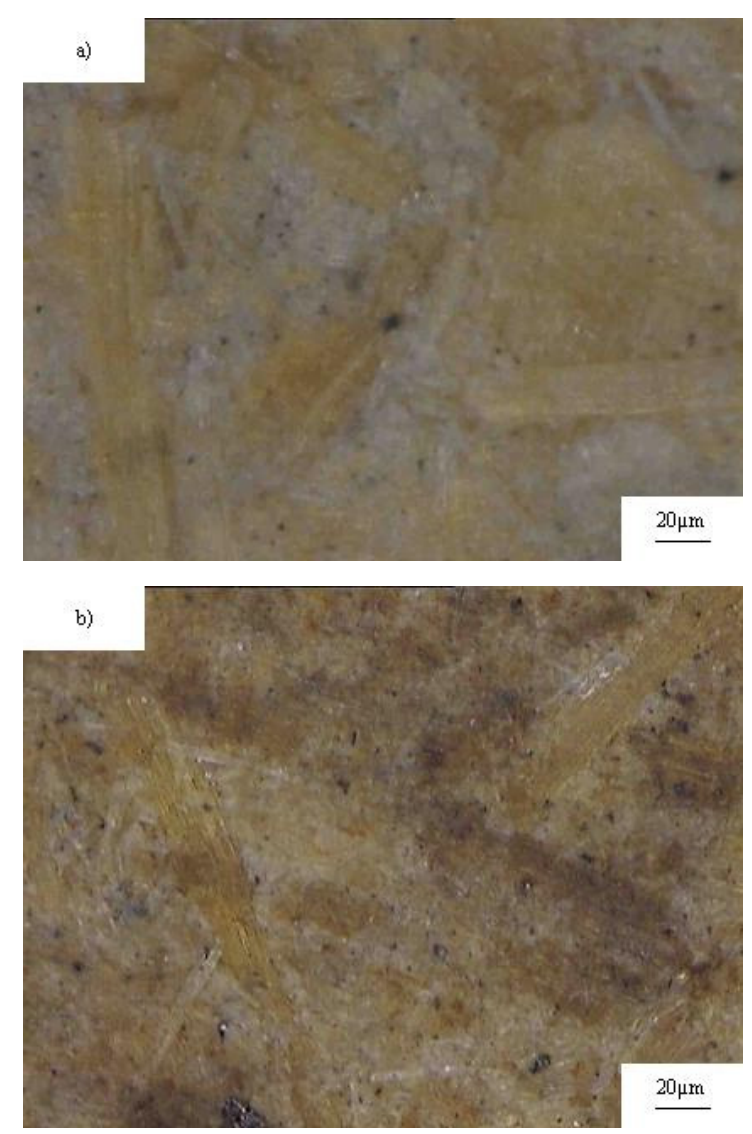

c)
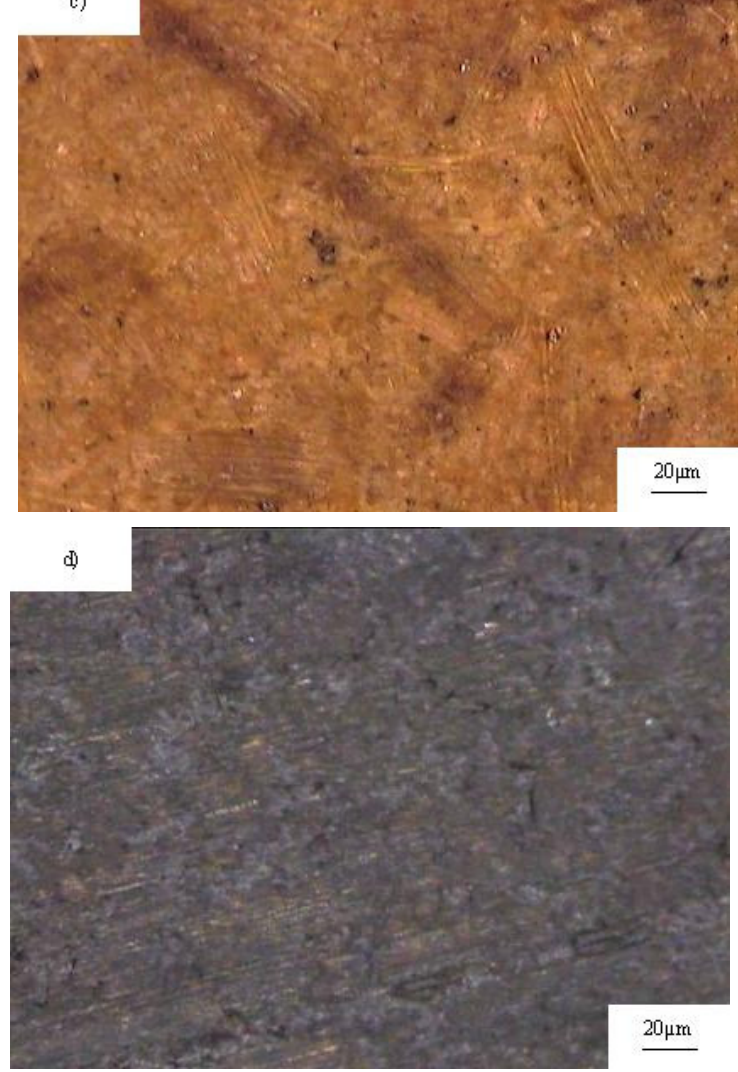

Figure 4. Photographs of specimen (top view)

a) 160 , b) 180 , c) 200 and d) $240^{\circ} \mathrm{C}$ 


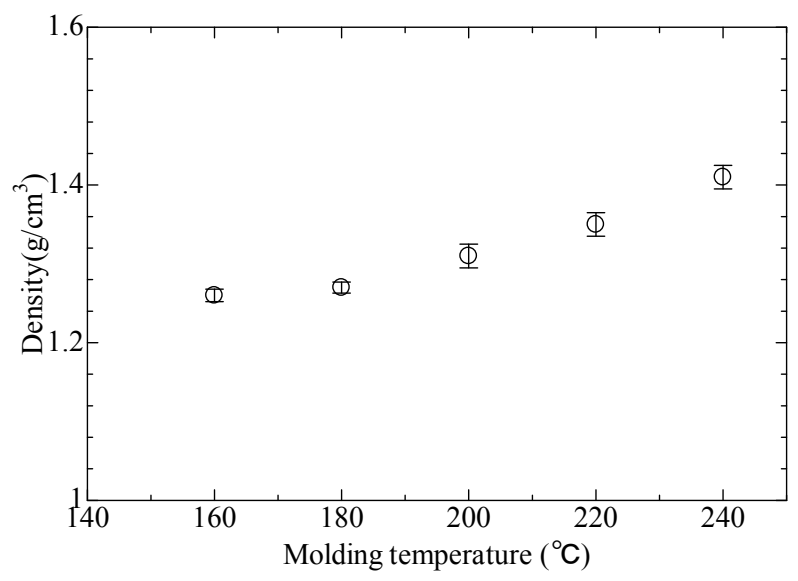

Figure 5. Relationship between density and molding temperature

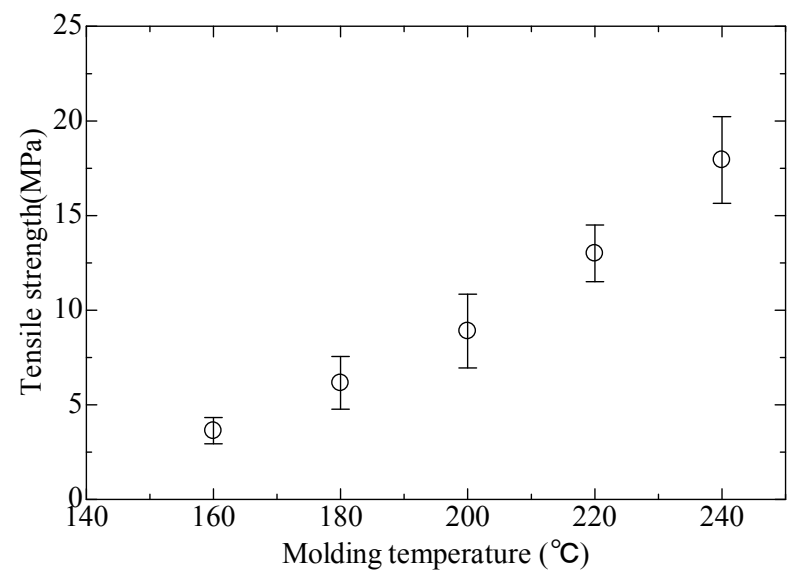

Figure 6. Relationship between tensile strength and molding temperature

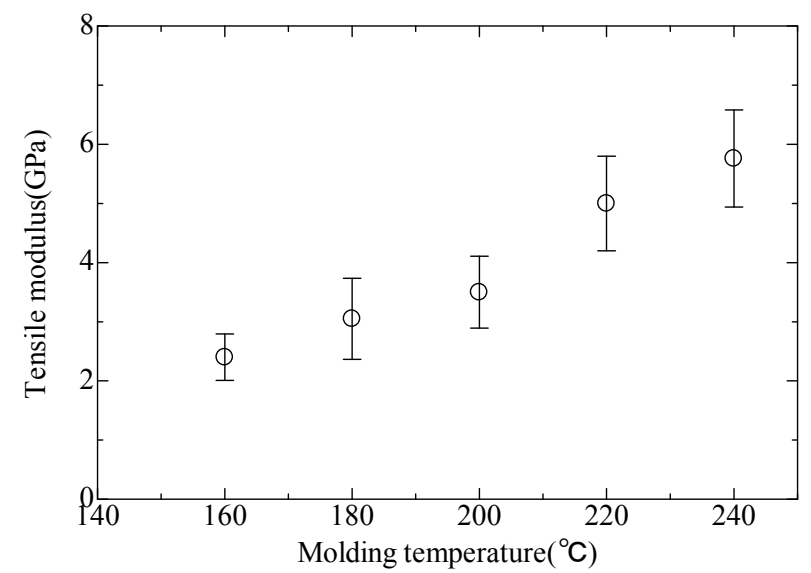

Figure 7. Relationship between tensile modulus and molding temperature 

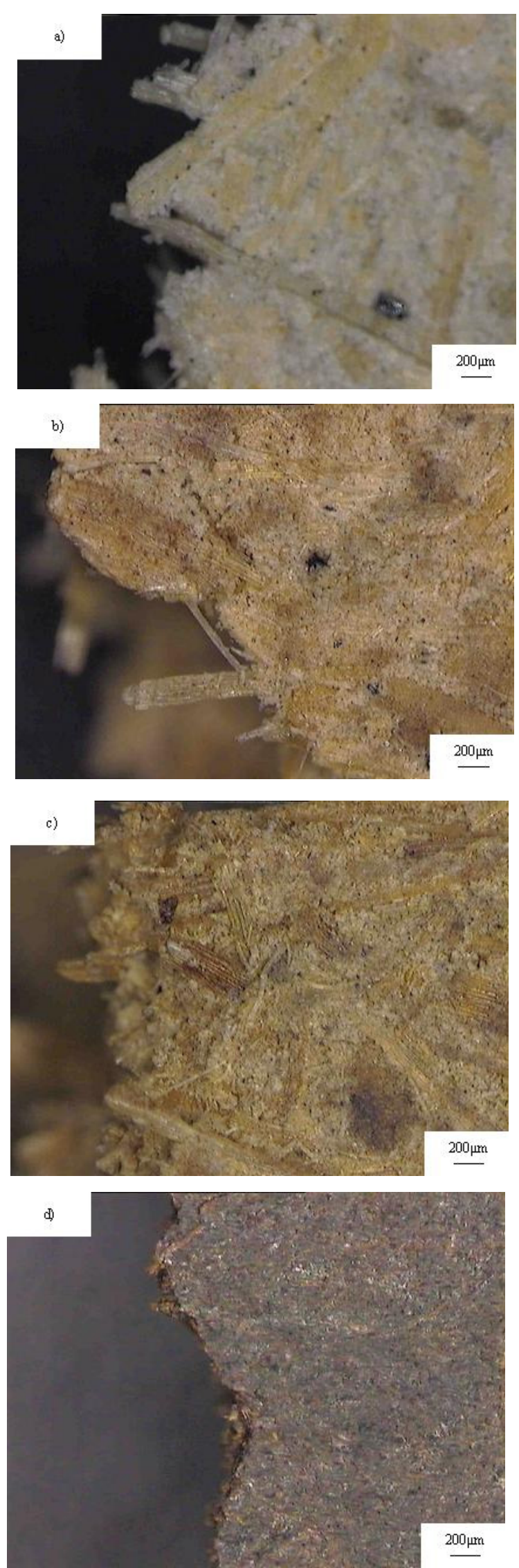

Figure 8 . Fracture behavior of tensile specimens: a) 160 , b) 180 , c) 200 and d) $240^{\circ} \mathrm{C}$ 


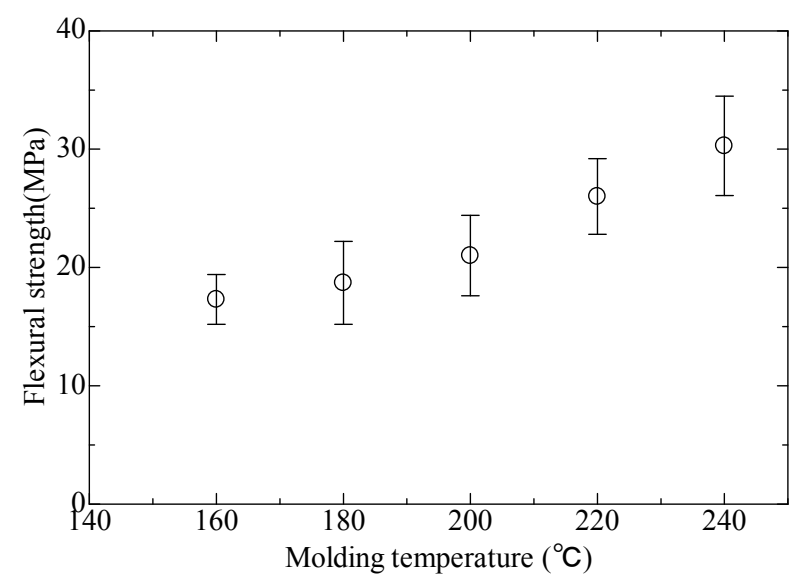

Figure 9. Relationship between flexural strength and molding temperature

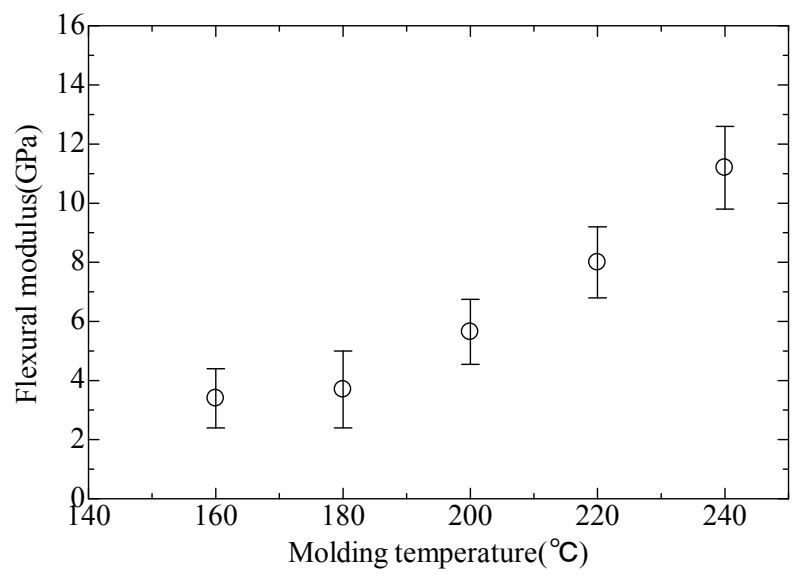

Figure 10. Relationship between flexural modulus and molding temperature 

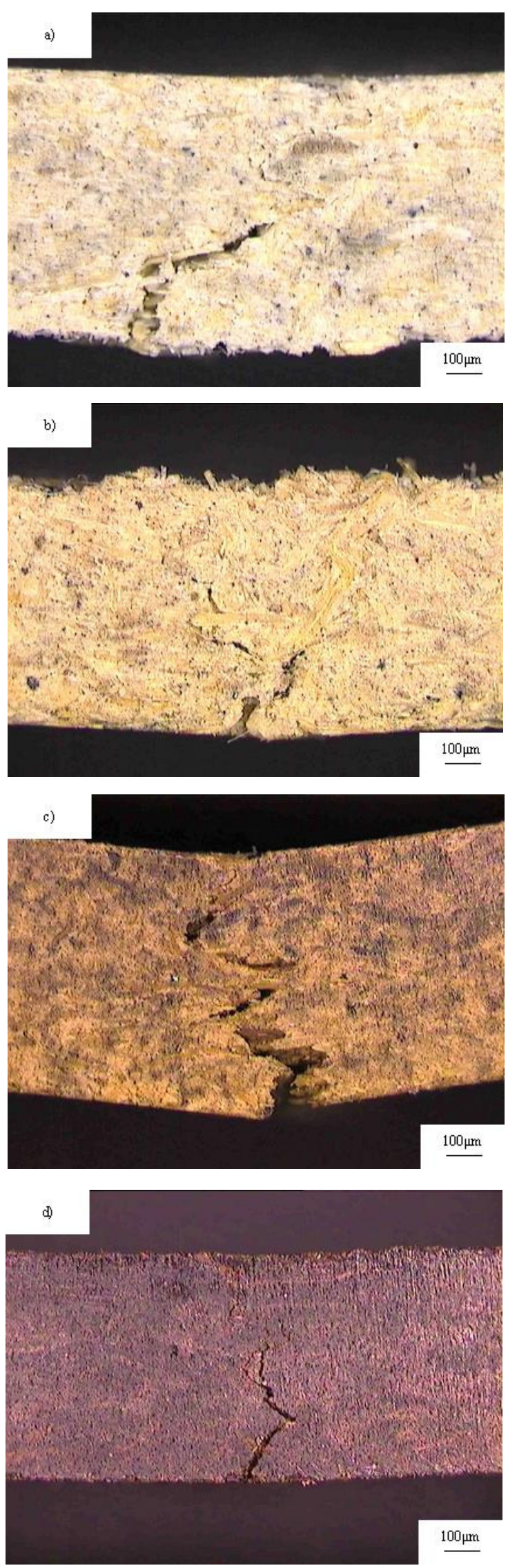

Figure 11. Fracture behavior of flexural specimens: a) 160 , b) 180 , c) 200 and d) $240^{\circ} \mathrm{C}$ 


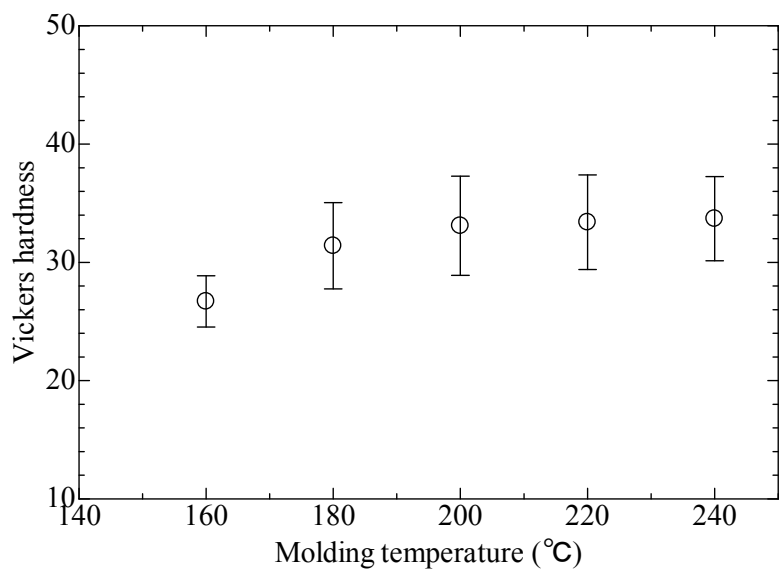

Figure 12. Relationship between Vickershardness and molding temperature 